\title{
Re: Erectile Dysfunction in Patients with Chronic Renal Failure
}

Leonardo E. Messina, Joaquim A. Claro, Archimedes Nardozza, Enrico Andrade, Valdemar Ortiz, Miguel Srougi

Section of Urology, Paulista School of Medicine, Federal University of Sao Paulo, UNIFESP, Sao Paulo, SP, Brazil

Int Braz J Urol, 33: 673-678, 2007

To the Editor:

Erectile dysfunction is an important cause of quality of life limitation (1). Messina et al. evaluate erectile dysfunction (ED) in chronic renal failure (CRF). Their cross-study showed the prevalence of ED among 58 patients in hemodialysis program.

The prevalence of their study was $31.4 \%$ and $68.6 \%$ between patients younger and older than 50 years, respectively. Age, diabetes mellitus \& hemodialysis characteristic were associated with higher incidence of ED (2), while they found that neither hypertension (even it is common) nor the duration of dialysis are associated with ED. They brilliantly suggest to all physician and all health professional to pay more attention to their patients' sexual problems.

With high respect to Messina and his colleagues, we want to give some comment on their study:

1) Assessment of ED is done by International Index of Erectile Function-5 (IIEF-5) $(3,4)$.

2) Their study was done only on male patients. Indeed, women who suffered from CRF may have ED. Therefore, for assessment of ED in women patients, Index of Female Sexual Function (IFSF) should be asked (5).

3) ED is a multifactor disease or as we say, symptom. Therefore, hypercholesterolemia, hyperlipidemia, hyper or hypo thyroidism, low blood zinc, low testosterone, high prolactin and even high parathyroid hormone are associated with ED $(4,5)$. Messina et al did not mention the measurement of such tests (2).
4) Obesity in CRF patients can cause ED (1).

5) There is no doubt that psychological problems are the important causes of ED. So all patients should be asked Beck Depression Inventory (BDI) to investigate their depression symptoms.

6) Bellinghieri et al. found ultrastructural changes of corpora cavernosa in uremic male patients. These changes are more evident in male patients with longer time on dialysis.

7) In our clinic, our evaluation of male patients for ED consists of taking and even drug history (e.g. antihypertensive, $\mathrm{H} 2$ blocker receptors, etc.), physical exam, measuring BUN, creatinine, FBS, cholesterol, triglyceride, HDL, LDL, testosterone, prolactin, thyroid and parathyroid function tests; and besides those, cavernosal injection of vasoactive agents, color Doppler sonography, cavernosography and cavernosometry and Rigiscan as needed.

\section{REFERENCES}

1. Esposito K, Giugziano F, Di Palo C, Giugliano G: Effect of lifestyle changes on erectile dysfunction in obese men; JAMA. 2004; 291: 2978-84.

2. Messina LE, Claro JA, Nardozza A, Andrade E, Ortiz V, Srougi M: Erectile dysfunction in patients with chronic renal failure. Int Braz J Urol. 2007; 33: 673-8.

3. Lue TF, Broderick G: Evaluation and Nonsurgical Management of Erectile Dysfunction and Priapism. In: Walsh PC, Retik AB, Vaughn ED, Wein AJ (eds.), Campbell's Urology. 7th ed. Philadelphia, Saunders, 1998, pp. 1181-1214. 
4. Fung MM, Bettencourt R, Barrett-Connor E: Heart disease risk factors predict erectile dysfunction 25 years later: the Rancho Bernardo Study. J Am Coll Cardiol. 2004; 43: 1405-11.

5. Lai CF, Wang YT, Hung KY, Peng YS, Lien YR, Wu MS, et al.: Sexual dysfunction in peritoneal dialysis patients, Am J Nephrol. 2007, 27: 615-21.
6. Bellinghieri G, Santoro G, Santoro D, Lo Forte B, Savica V, Favazzi P, et al.: Ultrastructural changes of corpora cavernosa in men with erectile dysfunction and chronic renal failure, Semin Nephrol. 2004; 24: 488491.

Dr. Ali Shamsa

Dr. M. Javad Mojahedi

Departments of Urology, Nephrology \& Kidney transplantation, Ghaem Hospital Mashhad University of Medical Sciences

Mashhad, Iran

E-mail: shamsa@mums.ac.ir

\section{Re: Erectile Dysfunction in Patients with Chronic Renal Failure}

Leonardo E. Messina, Joaquim A. Claro, Archimedes Nardozza, Enrico Andrade, Valdemar Ortiz, Miguel Srougi

Section of Urology, Paulista School of Medicine, Federal University of Sao Paulo, UNIFESP, Sao Paulo, SP, Brazil

Int Braz J Urol, 33: 673-678, 2007

To the Editor:

The association of chronic renal failure (CRF) to erectile dysfunction (ED) is a well known fact, but the prevalence of ED obtained in this population is variable. The lack of an standardised instrument for ED assessment before generalisation of the international index of erectile function (IIEF) and the heterogeneity of CRF patients regarding the presence of commorbidities are two facts that have probably contributed to this variability. However, a high prevalence of ED has generally been reported in CRF patients. In this sense, Messina and collaborators report in this issue that the prevalence of ED in a 